\title{
The effect of positive-end expiratory pressure on oxygenation during high frequency jet ventilation and conventional mechanical ventilation in the rabbit model of acute lung injury
}

\author{
Jae Ouk Bang, Seung Il Ha, and In-Cheol Choi
}

Department of Anesthesiology and Pain Medicine, Asan Medical Center, University of Ulsan College of Medicine, Seoul, Korea

Background: The use of positive end expiratory pressure (PEEP) in patients with acute lung injury (ALI) improves arterial oxygenation by alleviating pulmonary shunting, helping the respiratory muscles to decrease the work of breathing, decreasing the rate of infiltrated and atelectatic tissues, and increasing functional residual capacity. In a rabbit model of saline lavage-induced ALI, we examined the effects of PEEP on gas exchange, hemodynamics, and oxygenation during high frequency jet ventilation (HFJV), and then compared these parameters with those during conventional mechanical ventilation (CMV).

Methods: Twelve rabbits underwent repeated saline lavage to create ALI. The animals were divided in 2 groups: 1) Group CMV ( $\mathrm{n}=6)$, and 2) Group HFJV ( $\mathrm{n}=6)$. In both groups, we applied 2 levels of PEEP $\left(5 \mathrm{cmH}_{2} \mathrm{O}\right.$ and $\left.10 \mathrm{cmH}_{2} \mathrm{O}\right)$ and then measured the arterial blood gas, mixed venous blood gas, and hemodynamic parameters.

Results: With administration of PEEP of either $5 \mathrm{cmH}_{2} \mathrm{O}$ or $10 \mathrm{cmH}_{2} \mathrm{O}$, the arterial oxygen content of both groups was increased, although without statistically significant differences between groups. On the contrary, the arterial carbon dioxide content was significantly decreased in the HFJV group, as compared with the CMV group, during the entire experiment. Furthermore, there was significant decreases in mean arterial pressures in both groups with a PEEP of 10 $\mathrm{cmH}_{2} \mathrm{O}$.

Conclusions: The application of PEEP in rabbits with ALI effectively improves oxygenation in either HFJV or CMV. (Korean J Anesthesiol 2012; 63: 346-352)

Key Words: Acute lung injury, High frequency jet ventilation, Positive-end expiratory pressure.

Received: May 10, 2012. Revised: July 12, 2012. Accepted: August 2, 2012.

Corresponding author: In-Cheol Choi, M.D., Department of Anesthesiology and Pain Medicine, Asan Medical Center, University of Ulsan College of Medicine, 388-1, Pungnap 2-dong, Songpa-gu, Seoul 138-736, Korea. Tel: 82-2-3010-3862, Fax: 82-2-3010-6790, E-mail: icchoi@amc.seoul.kr (c) This is an open-access article distributed under the terms of the Creative Commons Attribution Non-Commercial License (http:// creativecommons.org/licenses/by-nc/3.0/), which permits unrestricted non-commercial use, distribution, and reproduction in any medium, provided the original work is properly cited. 


\section{Introduction}

Acute lung injury (ALI) and acute respiratory distress syndrome (ARDS) were first described in 1967 as extensive pulmonary infiltrations accompanied by acute hypoxemia [1]. Each of these conditions has very high mortality and morbidity rates, and there are no known effective treatments [2]. Conventional mechanical ventilation (CMV) maintains gas exchange for patients suffering from the above conditions, and has played an important role in the improvement of these disorders. However, large tidal volumes and positive pressure ventilation damage alveolar epithelial cells, pulmonary capillary endothelial cells, and the basal membrane. The effects of CMV cause leakage of endovascular substances and air from the lungs. This eventually leads to alveolar volutrauma, and a vicious cycle of increasing time required on a ventilator, which can exacerbate lung injury and increase the mortality rate $[3,4]$.

To solve these problems, the methods involve the lowest possible tidal volume, methods involving permissive hypercarbia, an accompanying respiratory acidosis, and the reversal of inspiration and expiration times. In addition, there are ventilation methods in both research and in practice that can replace CMV and adjuvant ventilation therapies, and these have been evaluated as clinically effective in treating ARDS patients, while reducing ARDS-related mortality rates $[5,6]$.

In contrast to CMV, which involves the repetition of expansion and constriction with large tidal volumes, high frequency ventilation (HFV) is performed with a tidal volume that is less than the dead space and respiratory rates that are increased above physiologic levels. Thus, during HFV, lung volumes are kept relatively stable throughout the entire respiratory cycle, and lung injury from heterogenous lung expansion and high airway pressures is reduced, gas exchange is improved, and the inflammatory response is minimized [7-9]. Other methods of HFV are also practiced clinically, such as high frequency jet ventilation (HFJV), high frequency oscillation (HFO), and high frequency flow interruption [10,11].

When assisting respiration in ALI patients, the application of positive end expiratory pressure (PEEP) minimizes the non-ventilated lung volume and increases functional residual capacity. As a result, PEEP can reduce pulmonary shunting, improve oxygenation, increase oxygen saturation of red blood cells, and reduce inspiratory oxygen requirements [12].

If a closed respiratory circuit is used for HFJV, the application of PEEP is known to be possible [13]. The PEEP during HFJV will optimize the lung volume recruitment and improve the oxygenation. But, excessive PEEP is associated with increased risk for lung injury and cardiopulmonary implications.

Using a rabbit model of saline-induced lung injury, we aimed to compare the effect of PEEP during HFJV to the effect of PEEP during CMV on oxygenation, gas exchange, and hemodynamics. We hypothesized that the application of PEEP during HFJV would have the same effect on improving oxygenation as it does during CMV. In addition, we have determined the appropriate level of PEEP improved oxygenation without significantly reducing hemodynamic profiles.

\section{Materials and Methods}

\section{Preparation of the laboratory animals}

After receiving the approval of the Ethics Committee for Animal Studies, 12 male New Zealand white rabbits weighing $2.8-3.8 \mathrm{~kg}$ were randomly divided into groups undergoing either CMV (Group CMV, $\mathrm{n}=6$ ) or HFJV (Group HFJV, $\mathrm{n}=6$ ). The rabbits were sedated by intramuscular administration of Xylazine (3 mg/kg) (Rumpun ${ }^{\circledR}$, Bayer, Korea) and Tiletamine/ zolazepam (1-2 mg/kg) (Zoletil ${ }^{\circledR}$, Virbag, Carros, France), in the gluteal muscle. Heating pads were fixed on the surgical table, and a $22 \mathrm{G}$ catheter was placed in the marginal ear vein to secure intravenous access. Normal saline and 6\% hydroxyl ethyl starch (Voluven ${ }^{\circledR}$, Fresineus Kabi, Germany), mixed in a $1: 1$ ratio, were infused continuously at $10 \mathrm{ml} / \mathrm{kg} / \mathrm{hr}$. A tracheostomy was performed so that a $4 \mathrm{~mm}$ diameter endotracheal tube could be inserted, which was then secured at a depth of 3-4 $\mathrm{cm}$ by ligation with surgical thread. During the maintenance of anesthesia, xylazine $(2 \mathrm{mg} / \mathrm{kg} / \mathrm{hr}$ ) was administered for sedation, and vecuronium (Norcuron ${ }^{\circledR}$, Organon, Korea) was bloused ( $1 \mathrm{mg} / \mathrm{kg}$ ) and then continuously infused at $1 \mathrm{mg} /$ $\mathrm{kg} / \mathrm{hr}$ for muscle relaxation. Arterial access was secured with a $22 \mathrm{G}$ catheter in the right femoral artery, which was used for the continuous measurement of arterial pressure and the intermittent collecting of blood. A 4 Fr thermistor-tipped SwanGanz catheter (Arrow International Inc., USA) was inserted into the right internal jugular vein for the continuous measurement of pulmonary arterial pressures and core body temperature.

\section{Lung injury}

The ALI model by lung lavage was based on the method described by Lachmann et al. [14]. After disconnecting the endotracheal tube from the ventilator, normal saline $(15 \mathrm{ml} / \mathrm{kg}$, heated to $38-39^{\circ} \mathrm{C}$ ) was infused evenly into the lungs through the endotracheal tube. After about 1 min of ventilation using the Harvard respirator (Harvard Apparatus, USA), the infused normal saline was removed by natural drainage or aspiration. Lung lavage by normal saline was then repeated at 5-7 min intervals. Oxygen saturation $\left(\mathrm{SpO}_{2}\right)$ was continuously measured from the tongue of the rabbit. When the $\mathrm{SpO}_{2}$ fell to $90 \%$ or below, the lung lavages were stopped, and an arterial blood gas 
analysis was performed. If oxygen tension decreased to about $100 \mathrm{mmHg}$, the experiments were preceded to the next steps.

\section{Ventilation method}

Group CMV was ventilated with the Harvard respirator. The following settings were used to maintain an arterial carbon dioxide $\left(\mathrm{PaCO}_{2}\right)$ of 35-40 mmHg: tidal volume, $8-12 \mathrm{ml} /$ $\mathrm{kg}$; respiratory rate, $20-30 \mathrm{bpm}$; ratio of inspiratory time to expiratory time (I : E ratio), $1: 1$; and fraction of inspired oxygen $\left(\mathrm{FiO}_{2}\right)$, 1.0. In Group HFJV, a $14 \mathrm{G}$ spinal needle with its tip cut off was inserted through the endotracheal tube and connected to the HFJ ventilator (Bromsgrove humidified jet ventilator, Penlon, UK). Ventilation was performed at the following settings: respiratory rate, 120; driving pressure, 2 psi; and $\mathrm{FiO}_{2}$, 1.0. Lung lavage was performed on both groups $1 \mathrm{~h}$ after hemodynamic stability was achieved. After ALI was confirmed, a PEEP of $5 \mathrm{cmH}_{2} \mathrm{O}$ and then a PEEP of $10 \mathrm{cmH}_{2} \mathrm{O}$ were applied to both groups. For the application of PEEP, a $20 \mathrm{~cm}$ beaker filled completely with water was placed on an experiment board at the same level as the rabbit. The expiratory port of the ventilator was placed at a depth of $5 \mathrm{~cm}$ or $10 \mathrm{~cm}$ so that at expiration, the appropriate PEEP would be exerted due to the water (Fig. 1). Each time PEEP was applied, a 15 min stabilization period was given. After all the results were assessed, the rabbits were euthanized with potassium chloride $(\mathrm{KCl})$ by intravenous administration.

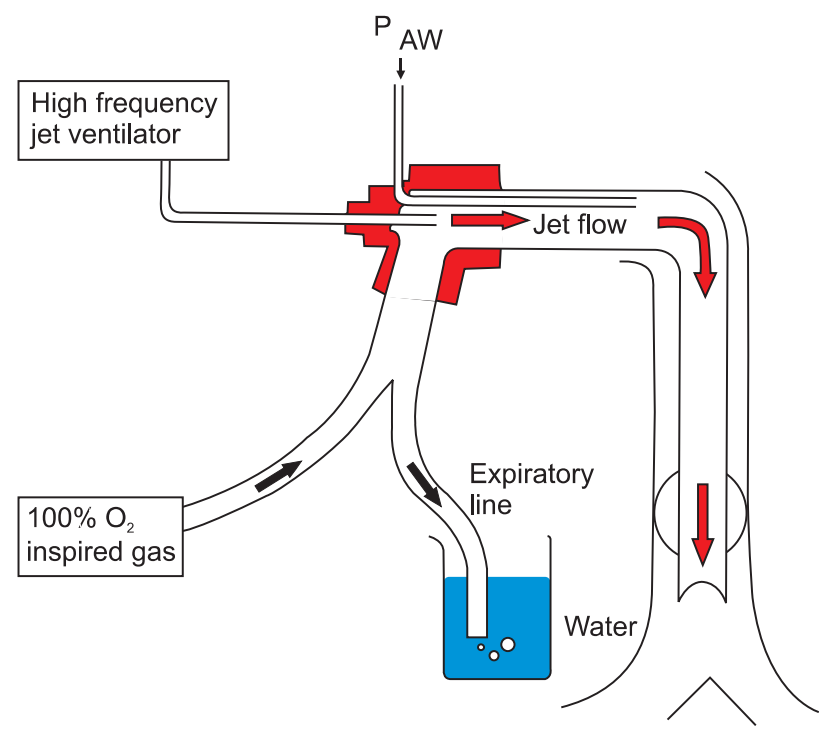

Fig. 1. High-frequency jet ventilation and PEEP. This figure shows the method of how to apply high frequency jet ventilation and PEEP. The 20 -cm deep beaker filled with water was put on the testing bench at the same height as the rabbit. The expiratory port was placed in the water at a depth of $5 \mathrm{~cm}$ and $10 \mathrm{~cm}$ to generate PEEP during HFJV.

\section{Experiment values}

The experiment values were taken at the following 4 points: 1) baseline (B) when the experiment preparations were completed; 2) the point when ALI was confirmed (point ALI); 3) the point after a PEEP of $5 \mathrm{cmH}_{2} \mathrm{O}$ was applied (PEEP 5); and 4) the point after a PEEP of $10 \mathrm{cmH}_{2} \mathrm{O}$ was applied (PEEP 10). For each group, arterial blood and mixed venous blood gas analyses were performed; the heart rate, mean arterial pressure, pulmonary arterial pressure, core body temperature, pulse oximetry, and peak airway pressures (Paw) were measured; and the alveolar-arterial oxygen tension difference $\left(\mathrm{AaDO}_{2}\right)$ was calculated.

\section{Statistics}

All data are reported as mean \pm standard error, and a P value less than 0.05 was considered statistically significant. SPSS (version 12.0, Chicago, IL) was used for statistical analyses. Comparisons within each group were performed with the Friedman's test, and post-hoc testing was done using the Wilcoxon signed rank test. Comparisons of the groups were performed with the Mann-Whitney U test.

\section{Results}

The weights of the rabbits did not differ between groups (Group CMV: $3.1 \pm 0.2 \mathrm{~kg}$; Group HFJV: $3.2 \pm 0.1 \mathrm{~kg}$ ). Blood pressure, pulmonary arterial pressure, $\mathrm{SpO}_{2}$, heart rate, and the arterial oxygen content $\left(\mathrm{PaO}_{2}\right)$, taken after the experiment preparations, did not differ between groups. However, both body temperature and $\mathrm{PaCO}_{2}$ were lower in Group HFJV compared with Group CMV (Table 1 and 2). Overall, lavage with normal saline was performed $2-4$ times, with average volumes of $57 \pm 5 \mathrm{ml}$ in Group CMV and $53 \pm 3 \mathrm{ml}$ in Group HFJV.

There were initially no differences between the two groups in terms of mean blood pressure; however, the mean blood pressure was progressively reduced for each group after the addition of PEEP. For Group CMV, the mean blood pressure dropped after the addition of $5 \mathrm{cmH}_{2} \mathrm{O}$ of PEEP, and more dropped after the addition of $10 \mathrm{cmH}_{2} \mathrm{O}$ of PEEP. Likewise, in Group HFJV, the mean blood pressure dropped after the addition of $5 \mathrm{cmH}_{2} \mathrm{O}$ of PEEP, and more dropped after the addition of $10 \mathrm{cmH}_{2} \mathrm{O}$ of PEEP (Fig. 2).

The body temperature in Group CMV was significantly lower than at baseline, and in Group HFJV it became significantly lower at each experimental stage. When the two groups were compared, Group HFJV showed a lower body temperature than Group CMV at baseline, at a PEEP of $5 \mathrm{cmH}_{2} \mathrm{O}$, and at a PEEP of $10 \mathrm{cmH}_{2} \mathrm{O}$ (Fig. 3). Otherwise, there were no significant 
Table 1. Hemodynamic Data

\begin{tabular}{|c|c|c|c|c|c|}
\hline & & B & ALI & PEEP 5 & PEEP 10 \\
\hline \multirow[t]{2}{*}{$\mathrm{mABP}(\mathrm{mmHg})$} & CMV & $62.3 \pm 4.5$ & $68.7 \pm 6.7$ & $59.2 \pm 4.9^{\ddagger}$ & $48.8 \pm 3.7^{\ddagger, \S}$ \\
\hline & HFJV & $53.5 \pm 5.5$ & $57 \pm 3.5$ & $49.7 \pm 5.3$ & $41.5 \pm 5.6^{\ddagger . \S}$ \\
\hline \multirow[t]{2}{*}{ mPAP (mmHg) } & CMV & $11.4 \pm 1.1$ & $12 \pm 2.5$ & $12.6 \pm 1.5$ & $12.4 \pm 2.1$ \\
\hline & HFJV & $11.4 \pm 1.7$ & $11 \pm 2.2$ & $11 \pm 2.7$ & $13 \pm 3.8$ \\
\hline \multirow[t]{2}{*}{ HR (beats/min) } & CMV & $180.2 \pm 40.5$ & $223.2 \pm 34.7$ & $214.4 \pm 26.4$ & $208 \pm 2$ \\
\hline & HFJV & $205 \pm 9.7$ & $206.4 \pm 20$ & $199 \pm 20.8$ & $200.4 \pm 27.3$ \\
\hline \multirow[t]{2}{*}{ Paw (mmHg) } & CMV & $11 \pm 2.2$ & $19.4 \pm 3.1^{\dagger}$ & $22.4 \pm 3.7^{\dagger}$ & $27.6 \pm 4.7^{\dagger, \ddagger}$ \\
\hline & HFJV & $9.8 \pm 3.4$ & $16 \pm 2.1^{\dagger}$ & $19.4 \pm 2.9^{\dagger, \uparrow}$ & $23.2 \pm 5.2^{\dagger, \uparrow, \S}$ \\
\hline \multirow[t]{2}{*}{ Temp $\left({ }^{\circ} \mathrm{C}\right)$} & CMV & $39 \pm 0.3$ & $38.3 \pm 0.3^{\dagger}$ & $38.4 \pm 0.3^{\dagger}$ & $38.4 \pm 0.3^{\dagger}$ \\
\hline & HFJV & $38.4 \pm 0.3^{*}$ & $37.8 \pm 0.4^{\dagger}$ & $37.5 \pm 0.4^{*, \dagger, キ}$ & $37.3 \pm 0.4^{*,+, \neq, \S}$ \\
\hline
\end{tabular}

Values are mean \pm SEM. B: baseline, ALI: acute lung injury, PEEP 5: PEEP of $5 \mathrm{cmH}_{2} \mathrm{O}$, PEEP 10: PEEP of $10 \mathrm{cmH}_{2} \mathrm{O}, \mathrm{CMV}_{\mathrm{c}}$ conventional mechanical ventilation, HFJV: high frequency jet ventilation, mABP: mean arterial blood pressure, mPAP: mean pulmonary arterial pressure, HR: heart rate, Paw: peak airway pressure, Temp: temperature ${ }^{*} \mathrm{P}<0.05$ compared with $\mathrm{CMV},{ }^{\dagger} \mathrm{P}<0.05$ compared with $\mathrm{B},{ }^{\dagger} \mathrm{P}<0.05$ compared with ALI, ${ }^{\S} \mathrm{P}<0.05$ compared with PEEP of $5 \mathrm{cmH}_{2} \mathrm{O}$.

Table 2. Respiratory Data

\begin{tabular}{|c|c|c|c|c|c|}
\hline & & B & ALI & PEEP 5 & PEEP 10 \\
\hline \multirow[t]{2}{*}{$\mathrm{PaO}_{2}(\mathrm{mmHg})$} & CMV & $376 \pm 19.7$ & $114.2 \pm 3.9^{\dagger}$ & $318 \pm 23.7^{\ddagger}$ & $396.6 \pm 24.2^{\ddagger, \S}$ \\
\hline & HFJV & $320 \pm 48.4$ & $125.7 \pm 32.3^{\dagger}$ & $307.2 \pm 48.2^{\ddagger}$ & $384.6 \pm 34.7^{\ddagger . \S}$ \\
\hline \multirow{2}{*}{$\mathrm{PaCO}_{2}(\mathrm{mmHg})$} & CMV & $37.1 \pm 4.7$ & $42.8 \pm 3.9$ & $35.1 \pm 2.9$ & $36.2 \pm 3.5$ \\
\hline & HFJV & $14.9 \pm 4.4^{*}$ & $21.2 \pm 3.4^{*}$ & $15 \pm 2.4^{*, \mp}$ & $10.9 \pm 1^{*, \neq, \S}$ \\
\hline \multirow[t]{2}{*}{$\mathrm{AaDO}_{2}(\mathrm{mmHg})$} & CMV & $297.7 \pm 18$ & $558.8 \pm 3.6^{\dagger}$ & $351.2 \pm 25.2^{\ddagger}$ & $271.1 \pm 24.6^{\neq . \S}$ \\
\hline & HFJV & $298.2 \pm 23.1$ & $534.7 \pm 38.6^{\dagger}$ & $313.9 \pm 58.3^{\ddagger}$ & $221.3 \pm 42.6^{\ddagger . \S}$ \\
\hline \multirow[t]{2}{*}{$\mathrm{SpO}_{2}(\%)$} & CMV & $100 \pm 0$ & $99.4 \pm 0.9$ & $100 \pm 0$ & $100 \pm 0$ \\
\hline & HFJV & $100 \pm 0$ & $98.6 \pm 1.7$ & $99.7 \pm 0.9$ & $99.8 \pm 0.5$ \\
\hline
\end{tabular}

Values are mean \pm SEM. B: baseline, ALI: acute lung injury, PEEP 5: PEEP of $5 \mathrm{cmH}_{2} \mathrm{O}$, PEEP 10: PEEP of $10 \mathrm{cmH}_{2} \mathrm{O}, \mathrm{CMV}_{\text {: conventional }}$ mechanical ventilation, HFJV: high frequency jet ventilation, $\mathrm{AaDO}_{2}$ : alveolar-arterial oxygen tension gradient, ${ }^{*} \mathrm{P}<0.05$ compared with $\mathrm{CMV}$, ${ }^{\dagger} \mathrm{P}<0.05$ compared with $\mathrm{B},{ }^{\dagger} \mathrm{P}<0.05$ compared with ALI, ${ }^{\S} \mathrm{P}<0.05$ compared with PEEP of $5 \mathrm{cmH}_{2} \mathrm{O}$.

differences between the two groups in terms of pulmonary arterial pressure, $\mathrm{SpO}_{2}$, or heart rate (Table 1 and 2).

After the lung injury in Group CMV, the $\mathrm{PaO}_{2}$ initially decreased to $120.1 \pm 31.5 \mathrm{mmHg}$. After the application of PEEP at levels of $5 \mathrm{cmH}_{2} \mathrm{O}$ and $10 \mathrm{cmH}_{2} \mathrm{O}$, the $\mathrm{PaO}_{2}$ increased to 328 $\pm 58.4 \mathrm{mmHg}$ and $409.9 \pm 55.4 \mathrm{mmHg}$, respectively (Fig. 4). Similarly, after the lung injury in Group HFJV, the $\mathrm{PaO}_{2}$ initially decreased to $133.8 \pm 85.5 \mathrm{mmHg}$, but after the application of PEEP at levels of $5 \mathrm{cmH}_{2} \mathrm{O}$ and $10 \mathrm{cmH}_{2} \mathrm{O}$, the $\mathrm{PaO}_{2}$ rose to 337.3 $\pm 103.1 \mathrm{mmHg}$ and $388.9 \pm 94.3 \mathrm{mmHg}$, respectively. Although both groups showed a significant difference among $\mathrm{PaO}_{2}$ levels after lung injury compared to those at baseline, and although $\mathrm{PaO}_{2}$ levels rose significantly for both groups after PEEP application, there were no differences between the CMV and HFJV groups.

In regards to $\mathrm{PaCO}_{2}$ levels, there were no significant changes in Group CMV during the experiment. In Group HFJV on the other hand, $\mathrm{PaCO}_{2}$ levels dropped after the addition of $5 \mathrm{cmH}_{2} \mathrm{O}$ of PEEP, and more dropped after the addition of $10 \mathrm{cmH}_{2} \mathrm{O}$ of PEEP. During the entire experimental period, Group HFJV showed significantly lower $\mathrm{PaCO}_{2}$ levels than Group CMV (Fig. 5).
The Paw not only increased significantly in both groups after the lung injury, it also increased at each stage of increased PEEP application (Table 1). Finally, the $\mathrm{AaDO}_{2}$ increased in both groups after the lung injury, but decreased after PEEP application, and there were no statistically significant differences between the 2 groups for this parameter (Table 1 ).

\section{Discussion}

The present study involved the lavage of rabbit lungs with normal saline in order to induce ALI. Gas exchange, oxygenation, and hemodynamic stability after PEEP application during HFJV were compared with those after PEEP application during CMV. Although the $\mathrm{PaO}_{2}$ initially decreased after saline-induced ALI, it clearly increased with the addition of PEEP in both CMV and HFJV groups. Furthermore, hemodynamic stability was maintained for both groups with the addition of $5 \mathrm{cmH}_{2} \mathrm{O}$ of PEEP, although blood pressure decreased for both groups upon applying $10 \mathrm{cmH}_{2} \mathrm{O}$ of PEEP.

Recent treatments for ARDS are aimed at supplementing oxygenation as much as possible, while preventing further lung 


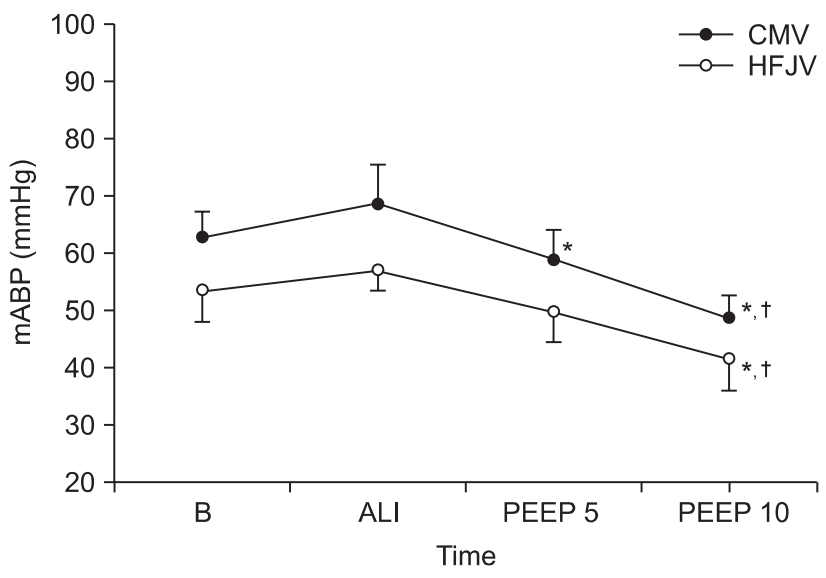

Fig. 2. The change in mean arterial blood pressure. Values are mean \pm SEM. B: baseline, ALI: acute lung injury, PEEP 5: PEEP of 5 $\mathrm{cmH}_{2} \mathrm{O}$, PEEP 10: PEEP of $10 \mathrm{cmH}_{2} \mathrm{O}, \mathrm{CMV}$ : conventional mechanical ventilation, HFJV: high frequency jet ventilation, mABP: mean arterial blood pressure, ${ }^{*} \mathrm{P}<0.05$ compared with ALI, ${ }^{\dagger} \mathrm{P}<0.05$ compared with PEEP of $5 \mathrm{cmH}_{2} \mathrm{O}$.

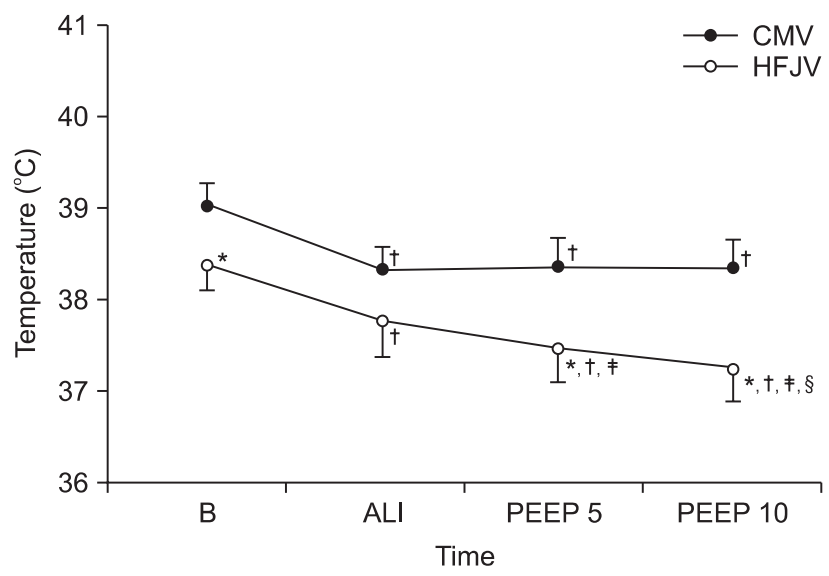

Fig. 3. The change in temperature. Values are mean \pm SEM. B: baseline, ALI: acute lung injury, PEEP 5: PEEP of $5 \mathrm{cmH}_{2} \mathrm{O}$, PEEP 10: PEEP of $10 \mathrm{cmH}_{2} \mathrm{O}, \mathrm{CMV}$ : conventional mechanical ventilation, HFJV: high frequency jet ventilation, ${ }^{*} \mathrm{P}<0.05$ compared with $\mathrm{CMV}$, ${ }^{\dagger} \mathrm{P}<0.05$ compared with $\mathrm{B},{ }^{\dagger} \mathrm{P}<0.05$ compared with ALI, ${ }^{\S} \mathrm{P}<0.05$ compared with PEEP of $5 \mathrm{cmH}_{2} \mathrm{O}$.

injury. The choice of ventilation for ARDS patients requires that which provides the fewest complications, most adequate oxygen supply, and the removal of $\mathrm{CO}_{2}$ to secure time for recovery from lung injury [12,15]. CMV in ALI patients may involve problems, such as high maximum inspiratory capacity and pressure, high mean airway pressure, a decrease in surfactant, and the possibility of mechanical damage from a ventilator [3]. Therefore, using existing ventilation methods, lung protective modes of ventilation are pursued, which use permissive hypercarbia accompanied by controlled respiratory acidosis, or the reversal of inspiration and expiration times. Moreover, high levels of

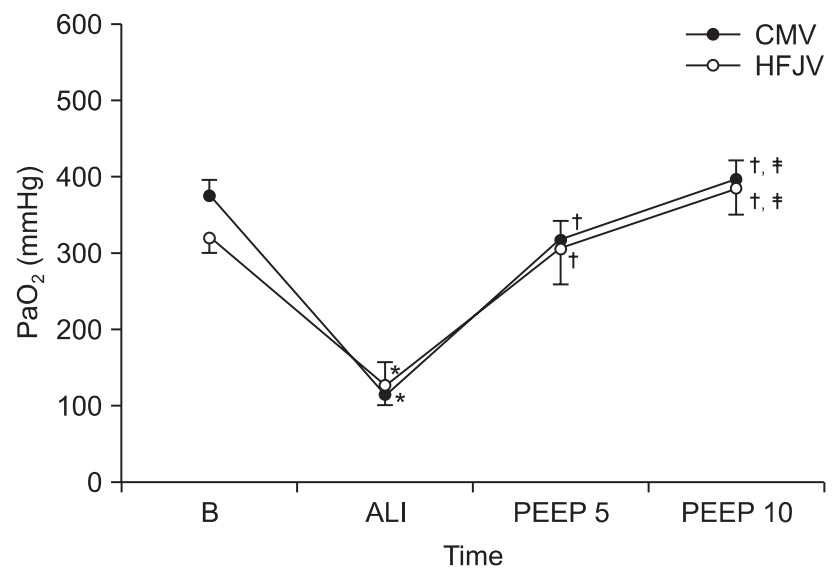

Fig. 4. The change in $\mathrm{PaO}_{2}$. Values are mean \pm SEM. B: baseline, ALI: acute lung injury, PEEP 5: PEEP of $5 \mathrm{cmH}_{2} \mathrm{O}$, PEEP 10: PEEP of 10 $\mathrm{cmH}_{2} \mathrm{O}$, CMV: conventional mechanical ventilation, HFJV: highfrequency jet ventilation, $* \mathrm{P}<0.05$ compared with $\mathrm{B},{ }^{\dagger} \mathrm{P}<0.05$ compared with ALI, ${ }^{\ddagger} \mathrm{P}<0.05$ compared with PEEP of $5 \mathrm{cmH}_{2} \mathrm{O}$.

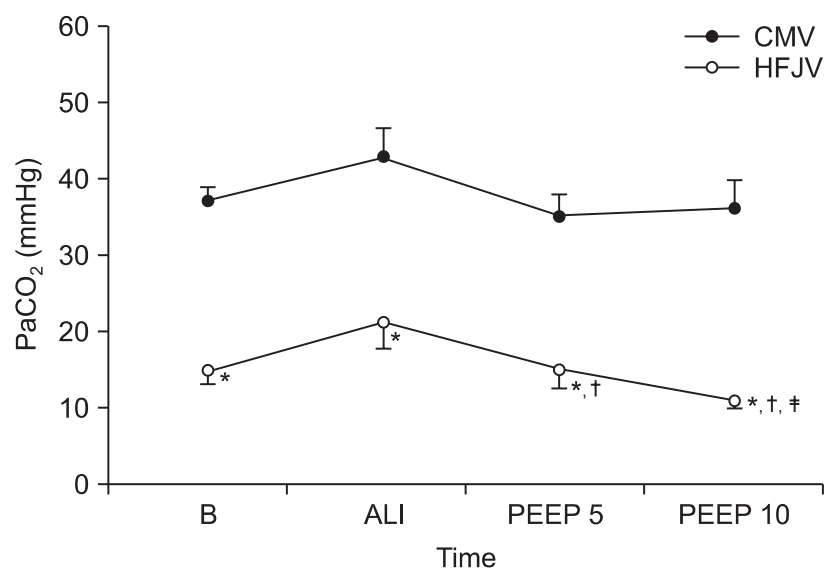

Fig. 5. The change in $\mathrm{PaCO}_{2}$. Values are mean \pm SEM. B: baseline, ALI: acute lung injury, PEEP 5: PEEP of $5 \mathrm{cmH}_{2} \mathrm{O}$, PEEP 10: PEEP of $10 \mathrm{cmH}_{2} \mathrm{O}, \mathrm{CMV}$ : conventional mechanical ventilation, HFJV: highfrequency jet ventilation, ${ }^{*} \mathrm{P}<0.05$ compared with $\mathrm{CMV},{ }^{\dagger} \mathrm{P}<0.05$ compared with ALI, ${ }^{\ddagger} \mathrm{P}<0.05$ compared with PEEP of $5 \mathrm{cmH}_{2} \mathrm{O}$.

maximum inspiratory pressure and overexpansion of the lungs can be avoided, but there is controversy over their effects $[5,16]$. For this reason, HFJV and liquid ventilation methods are used to decrease ventilator-associated lung injury [3].

HFJV, HFO, and high frequency flow interruption are clinically used methods for HFV $[10,11]$. The great advantage of HFV for those with ALI is that the high frequency beats cause turbulent flow, continuous ventilation of the alveoli, and the opening of closed airways. This results in a relative stabilization of lung capacity, the prevention of uneven alveolar expansion and atelectasis, the reduction of intrapulmonary shunt, and 
an increase in functional residual volume, which allows for adequate oxygenation with low maximum inspiratory pressure $[17,18]$. HFV is known as an effective approach to ALI, because the immune response to lung injury is altered when pressure changes are small and when hemodynamic stability is maintained [19]. However, there are potential complications with the use of HFV, such as airway damage, necrotic bronchitis, mucous retention, air trapping, air leakage, hemodynamic instability from high airway pressure application, and the hemorrhage of cerebral ventricles in neonates [20].

HFJV, as used in the present experiment, is a type of HFV that was introduced in 1977 as a treatment modality for ALI, such as those associated with pediatric respiratory distress syndrome and pulmonary air leakage [19]. HFJV constitutes the use of a high-pressure gas source, pressure-reducing valves with various inspiratory driving pressures, and a small-diameter jet catheter that connects to the respirometer through a smallvolume, non-elastic tube. Pressure differences determine the lung volume supplied by the jet ventilator according to the Bernoulli effect, as gas flows through the jet catheter at a very rapid speed. Additionally, expiration is passive, so caution against obstruction around the expiration site is necessary, and adequate humidification is required $[19,21]$.

In HFJV, gas exchange depends on: jet speed, mechanical properties of the ventilator, size of the catheter, driving pressure, respiratory frequency, I:E ratio, and PEEP [22,23]. Of these, PEEP has been known for some time to increase oxygenation in the setting of acute respiratory failure [24]. For patients with ARDS, the application of PEEP improves intrapulmonary shunts (despite clinical controversy), assists respiratory muscles by reducing the force needed for respiration, increases functional residual volume, and remobilizes collapsed alveoli to increase oxygenation [25]. Moreover, PEEP is also known to reduce the loss of surfactant and prevent lung collapse [26]. After the rabbit lungs were damaged by saline lavage in our study, we found that oxygenation was greatly improved, regardless if they were ventilated by CMV or HFJV. Moreover, the improvement of oxygenation after ALI tended to occur in an additive fashion, whereby more PEEP provided greater increases in $\mathrm{PaO}_{2}$, though the improvement in $\mathrm{PaO}_{2}$ was not as pronounced after adding $10 \mathrm{cmH}_{2} \mathrm{O}$ of PEEP, as when adding $5 \mathrm{cmH}_{2} \mathrm{O}$ of PEEP. These findings confirm that PEEP can be properly applied in HFJ ventilation using a closed respiratory circuit.

On the contrary, the side effects of PEEP include elevated thoracic pressures, reduction of venous return to the heart, compromised heart filling, and eventually reduced cardiac output and hypotension. Additionally, these side effects are most pronounced in hypovolemic patients [27]. Indeed, compared to immediately after pre-lung injury, we demonstrated a drop in blood pressure in Group CMV with the addition of $5 \mathrm{cmH}_{2} \mathrm{O}$ of
PEEP after ALI. Furthermore, when a PEEP of $10 \mathrm{cmH}_{2} \mathrm{O}$ was applied, both Group CMV and Group HFJV had clear drops in blood pressure, indicating that greater amounts of PEEP were decreasing blood pressure even more. In addition, HFV is known to cause less intrathoracic pressure changes than CMV, which should maintain hemodynamic stability [20]. However, we could not identify such an effect in our study, and Group HFJV actually had a lower blood pressure than Group CMV. We explain this observation by noting that Group HFJV had greater driving pressures, and the increase of expiratory lung volume from HFJV was considered to have similar effects on blood pressure as PEEP [10].

We acknowledge several areas of potential controversy. First, Group HFJV had a lower $\mathrm{PaCO}_{2}$ and body temperature than Group CMV for the entire experimental period. Initially, we had thought that the HFJV applied to the small rabbits was given at an adequate driving pressure and respiration frequency, but instead this may have caused hyperventilation. In fact, the HFJ ventilator that we used is intended for humans as opposed to animal testing, which likely gave greater tidal volumes to the rabbits than we had expected. The further reduce tidal volume would reduces the degree of reduction of $\mathrm{mABP}$ and body temperature and increase of Paw is also thought to have been reduced. Second, we may have not induced a severe enough degree of lung injury. There would have been $\mathrm{CO}_{2}$ retention had we made more serious lung injuries, and the benefit to HFJV compared with CMV might have been more easily identified. Third, neither the Harvard respirator nor the HFJ ventilator supports the mechanical application of PEEP. Therefore, in order to apply PEEP, the expiratory port of the ventilator was placed directly into water at depths of $5 \mathrm{~cm}$ and $10 \mathrm{~cm}$, yet the expiratory pressure and expiratory gas bubbles made it difficult to maintain and secure the expiratory port at the appropriate depth. However, the expiratory tube had been tightened as much as possible.

We conclude that the application of PEEP in rabbits with ALI effectively improves oxygenation in either HFJV or CMV. Additionally, because $5 \mathrm{cmH}_{2} \mathrm{O}$ of PEEP improved oxygenation without significantly reducing blood pressure, we believe that the use of low-level PEEP has a better risk-to-benefit profile than larger amounts of PEEP for the treatment of hypoxemia after ALI, with either HFJV or CMV.

\section{References}

1. Wheeler AP, Bernard GR. Acute lung injury and the acute respiratory distress syndrome: a clinical review. Lancet 2007; 369: 1553-64.

2. Ware LB, Matthay MA. The acute respiratory distress syndrome. N Engl J Med 2000; 342: 1334-49.

3. Parker JC, Hernandez LA, Peevy KJ. Mechanisms of ventilatorinduced lung injury. Crit Care Med 1993; 21: 131-43. 
4. Dreyfuss D, Saumon G. Ventilator-induced lung injury: lessons from experimental studies. Am J Respir Crit Care Med 1998; 157: 294-323.

5. Malhotra A. Low-tidal-volume ventilation in the acute respiratory distress syndrome. N Engl J Med 2007; 357: 1113-20.

6. Brower RG, Ware LB, Berthiaume Y, Matthay MA. Treatment of ARDS. Chest 2001; 120: 1347-67.

7. Fan E, Stewart TE. New modalities of mechanical ventilation: high-frequency oscillatory ventilation and airway pressure release ventilation. Clin Chest Med 2006; 27: 615-25.

8. Clark RH, Gerstmann DR, Null DM Jr, deLemos RA. Prospective randomized comparison of high-frequency oscillatory and conventional ventilation in respiratory distress syndrome. Pediatrics 1992; 89: 5-12.

9. Delemos RA, Coalson JJ, Gerstmann DR, Null DM Jr, Ackerman NB, Escobedo MB, et al. Ventilatory management of infant baboons with hyaline membrane disease: the use of high frequency ventilation. Pediatr Res 1987; 21: 594-602.

10. Huh IY, Jo MS, Choi IC. The effect of hihg frequency jet ventilation with partial liquid ventilation in saline lavaged lung injury in the rabbit. Korean J Anesthesiol 2004; 46: 96-108.

11. Sarnaik AP, Meert KL, Pappas MD, Simpson PM, Lieh-Lai MW, Heidemann SM. Predicting outcome in children with severe acute respiratory failure treated with high-frequency ventilation. Crit Care Med 1996; 24: 1396-402.

12. Delong P, Murray JA, Cook CK. Mechanical ventilation in the management of acute respiratory distress syndrome. Semin Dial 2006; 19: 517-24.

13. Barash PG, Cullen BF, Stoelting RK. Clinical Anesthesia. 6th ed. Philadelphia, LWW. 2006, p 1061.

14. Lachmann B, Robertson B, Vogel J. In vivo lung lavage as an experimental model of the respiratory distress syndrome. Acta Anaesthesiol Scand 1980; 24: 231-6.

15. Gattinoni L, Presenti A, Torresin A, Baglioni S, Rivolta M, Rossi F, et al. Adult respiratory distress syndrome profiles by computed tomography. J Thorac Imaging 1986; 1: 25-30.

16. Hickling KG, Walsh J, Henderson S, Jackson R. Low mortality rate in adult respiratory distress syndrome using low-volume, pressurelimited ventilation with permissive hypercapnia: a prospective study. Crit Care Med 1994; 22: 1568-78.

17. Takata M, Abe J, Tanaka H, Kitano Y, Doi S, Kohsaka T, et al. Intraalveolar expression of tumor necrosis factor-alpha gene during conventional and high-frequency ventilation. Am J Respir Crit Care Med 1997; 156: 272-9.

18. Abe K, Oka J, Takahashi H, Funatsu T, Fukuda H, Miyamoto Y. Effect of high-frequency jet ventilation on oxygenation during one-lung ventilation in patients undergoing thoracic aneurysm surgery. J Anesth 2006; 20: 1-5.

19. Klain M, Smith RB. High frequency percutaneous transtracheal jet ventilation. Crit Care Med 1977; 5: 280-7.

20. Kallas HJ. Non-conventional respiratory support modalities applicable in the older child. High frequency ventilation and liquid ventilation. Crit Care Clin 1998; 14: 655-83.

21. Carlon GC, Miodownik S, Ray C Jr, Kahn RC. Technical aspects and clinical implications of high frequency jet ventilation with a solenoid valve. Crit Care Med 1981; 9: 47-50.

22. Holzapfel L, Robert D, Perrin F, Gaussorgues P, Giudicelli DP. Comparison of high-frequency jet ventilation to conventional ventilation in adults with respiratory distress syndrome. Intensive Care Med 1987; 13: 100-5.

23. Rouby JJ, Simonneau G, Benhamou D, Sartene R, Sardnal F, Deriaz $\mathrm{H}$, et al. Factors influencing pulmonary volumes and CO2 elimination during high-frequency jet ventilation. Anesthesiology 1985; 63: 473-82.

24. Ashbaugh DG, Bigelow DB, Petty TL, Levine BE. Acute respiratory distress in adults. Lancet 1967; 2: 319-23.

25. Acosta P, Santisbon E, Varon J. The use of positive end-expiratory pressure in mechanical ventilation. Crit Care Clin 2007; 23: 251-61.

26. Rouby JJ, Lu Q, Goldstein I. Selecting the right level of positive end-expiratory pressure in patients with acute respiratory distress syndrome. Am J Respir Crit Care Med 2002; 165: 1182-6.

27. Pinsky MR. Cardiovascular issues in respiratory care. Chest 2005; 128(5 Suppl 2): S592-7. 